\title{
Understanding Factors Affecting the Adoption of ICT-Enabled Sustainable Supply Chain Management Practices
}

\author{
Chenxin Yao \\ University of Melbourne \\ cheyao@student.unimelb. \\ edu.au
}

\author{
Xiang Peng \\ University of Melbourne \\ xiang.peng@s.student.unim \\ elb.edu.au
}

\author{
Sherah Kurnia \\ University of Melbourne \\ sherahk@unimelb.edu.au
}

\author{
Mahbubur Rahim \\ Monash University \\ md.mahbubur.rahim@mo \\ nash.edu
}

\begin{abstract}
In recent years, a growing number of organizations have introduced sustainable supply chain management (SSCM) practices to enhance their economic, environment and social performance. SSCM practices are supported by information and communication technologies (ICT) to facilitate the coordination among the supply chain partners. Despite the importance of ICT-enabled SSCM practices, their adoption factors are still understudied. This study thus investigates factors affecting the adoption of ICT-enabled SSCM practices, using the Australian food industry as the study context. Through multiple case studies, we identify fifteen factors at the national, industry, supply chain, and organizational levels, including two new factors: environmental uncertainties and ICT resources of supply chain partners. Competitive pressure, though identified in the literature, is not found to be influential in our study. This study offers several implications to research and practice in SSCM.
\end{abstract}

\section{Introduction}

With rapid advancements in information and communication technologies (ICT), many organizations have extended their supply chains globally to take advantage of low-cost labor in developing countries [1]. ICT can be broadly defined as a combination of hardware, software, mobile devices, infrastructure, and networks that enables individuals and organizations to capture, store, process, manage and share data. While organizations gain economic benefits, extended supply chains and the processes involved generally have negative impacts on environment and society [2]. Food industry is a typical example. Specifically, $26 \%$ of anthropogenic greenhouse gas emissions come from the food supply chains, while $32 \%$ of global terrestrial acidification and $78 \%$ of eutrophication are created by food production [3]. These emissions can result in reduced biodiversity and ecological resilience and other negative impacts on the environment. In terms of social sustainability, food scandals (e.g., the 2018 Australian strawberry contamination) gave rise to public health issues and undermined the credibility of the food industry [4]. Therefore, the sustainability in food industry deserves more attention.

The public's growing sustainability awareness pressurizes organizations to implement sustainable supply chain management (SSCM), which is defined as the management of supply chain that takes into consideration economic, environmental and social aspects simultaneously [5]. SSCM practices require information sharing among the supply chain partners [6]. Therefore, the use of ICT to capture, store, process, manage and share data within and across organizations, is critical for SSCM [7].

Several studies have investigated the use of ICT in organizations' SSCM practices. For example, Zhong et al. [8] noted that emerging technologies such as the Internet of Things (IoT) were used to facilitate sustainable logistics operations through real-time data capturing and quality traceability. Moreover, there are studies that focus on IT-enabled SSCM capability maturity (e.g., Peng et al. [7]). However, there is a lack of research investigating factors influencing ICTenabled SSCM adoption.

To address this research gap, this study aims to investigate the factors affecting the adoption of ICTenabled SSCM practices in the food industry. Since Australia is one of the world leaders in food quality and safety [9], we anticipate that leading Australian food organizations have implemented various ICTenabled SSCM practices. Therefore, we consider the Australian food industry as an appropriate context for this study. Hence, our research question is:

What are key factors affecting the adoption of ICT-enabled SSCM practices in the Australian food industry?

We use multiple case studies to gain an in-depth understanding of the possible influential factors for the adoption of ICT-enabled SSCM practices in the Australian food industry. Fifteen adoption factors are identified, including two new factors: environmental 
uncertainties and the ICT resources of supply chain partners. Competitive pressure, though identified in the literature, is not found to be influential in our study.

In the next section, we synthesize previous literature on ICT-enabled SSCM practices in the food industry and possible adoption factors. The multiple case study method is then described, followed by the key findings and discussion. Finally, we conclude the paper and outline study contribution, limitations and future research.

\section{Literature review}

We conducted a literature review to understand the current state of knowledge in the related fields. A set of keywords such as SSCM practices, ICT and food industry were applied to identify ICT-enabled SSCM practices in the food industry. To identify the influencing factors, keywords such as SSCM practices adoption, factor/driver/barrier were used. About 100 relevant papers, published in key journals and conference proceedings in the last 10 years, were selected from multiple databases (e.g., SpringerLink, Scopus, etc.). Based on abstract review, 30 papers related to SSCM and cover the three sustainability aspects were selected for in-depth review and analysis.

\subsection{ICT-enabled SSCM practices in the food industry}

Drawing on our literature analysis, we have identified five types of ICT-enabled SSCM practices in the food industry: sustainable sourcing, sustainable processing, sustainable packaging, sustainable distribution, and sustainable marketing. Each of them is briefly explained below.

Sustainable sourcing links traditional purchasing activities with environmental and social considerations. The upstream suppliers are expected to adopt practices and technologies that lead to more environment-friendly and ethical agricultural produce [10]. Examples of ICT tools that enable these initiatives include collaborative platforms such as Sedex and EcoVadis, and cloud-based modules [11].

Sustainable processing aims to minimize the waste of resources (electricity, water, etc.) and food products, which contributes to improving ecoefficiency, reducing risks to the environment and finally enhancing company's environmental and operational performance [12]. The social performance can be improved by providing safer working condition and regular safety-related training [13].

Sustainable packaging aims to protect food products as they move along supply chains, maintain their quality, facilitate the storage and distribution process, as well as reduce the negative environmental impact to the minimum level [14]. Instant Life Cycle Assessment (LCA) Packaging is an example of software used to conduct LCA of food package [15].

Sustainable distribution involves systematic measurement, analysis, and mitigation of the environmental and social impact of distribution activities [16]. The use of ICT technologies such as Transportation Management Systems (TMS) and Radio Frequency Identification (RFID) allows companies to avoid unnecessary movements and have better visibility along the transportation process. Social aspects can be addressed by providing training and safe vehicles to employees [17].

Sustainable marketing is the promotion of environmentally and socially responsible products, services and activities as well as sustainable consumption concept to consumers [18]. The common initiatives include providing reliable information about the product to consumers through product labelling, launching education campaigns and communicating company's sustainability projects and performance with stakeholders [18].

\subsection{Factors affecting adoption of ICT-enabled SSCM practices}

From our literature analysis, 14 factors have been identified that are known to affect the adoption of ICTenabled SSCM practices. Drawing on multilevel classification proposed by Kurnia et al. [19], these factors are classified into four levels: national, industry, supply chain and organizational levels. Compared to the classification of factors into internal and external ones used by the majority of previous studies (e.g., Saeed and Kersten [20] and Sajjad et al. [21]), this multilevel classification is clearer and more elaborate in nature.

There are three factors at the national level. First, legislation (N1) refers to the existing and imminent regulations and policies developed by the government [20], such as environmental legislation that deals with industry emissions [22]. It is suggested that the immature governmental and legal regulations have a negative impact on companies' SSCM [6] and restrain their environmental proactivity [23].

Second, government support (N2) is related to various incentives and support provided by governments, which encourages organizations to proactively adopt sustainability actions [20]. Lesca et al. [24] stated that the lack of priorities, clear rules and other regulatory incentives could hinder the development of the organization's sustainable supply 
chain, and therefore hinder the implementation of supporting information systems.

The third factor is societal pressure (N3). Nongovernmental organizations (NGOs), media, communities and consumers raise organizations' awareness of sustainability [22]. For example, some NGOs developed globally recognized frameworks, such as the United Nations (UN) Global Compact and International Organization for Standardization 14000, to guide the integration of sustainability and supply chain management [20].

At the industry level, we identified two factors. First, industry standards and associations (I1) can influence the organizations' behaviors by creating sustainability-related standards and promoting the industry best practices [22]. It is suggested that the industry standard and certifications help to promote SSCM practices and the certified companies are more likely to adopt sustainability initiatives [20].

Another factor is competitive pressure (I2), which encourages organizations to make changes to keep up with their competitors' progress toward sustainability. Competitors who lead in adopting sustainability practices are more likely to set industry norms. As a result, organizations are under the pressure to follow those sustainability initiatives and achieve the samelevel sustainability performance $[25,26]$. Similarly, when competitors successfully implement advanced technologies, such peer pressure would motivate the organization to follow the trend so that they can maintain its competitive position [24, 27].

We identified two factors at the supply chain level. The first factor is the knowledge of supply chain partners (SC1) about sustainability [28]. Lack of knowledge about the concept of sustainability, nonstandardized sustainability performance measures and inconsistent performance measurement tools among supply chain members make it difficult to integrate the principles of sustainability into the supply chain [21, 28]. Besides, suppliers are reluctant to adopt new technologies and share information if they are not convinced of potential benefits [29].

Second, the cooperation of supply chain partners (SC2) refers to supply chain partners' willingness to work together and share information to achieve sustainability goals. It has an impact on both the implementation of the cross-organizational IT/IS [29, 30 ] and the incorporation of sustainability practices throughout the supply chain network [20]. It is suggested that the upstream collaboration helps to achieve a competitive advantage through SSCM [23] and enables organizational efficiencies [28].

Seven factors at the organizational level were identified. First, organizational culture (O1), which consists of collective values and beliefs, has an impact on the implementation of SSCM. A supportive culture for sustainability within the organization proves to be a prevailing enabler [23], as it helps to embed sustainability in the organizational values and core business [22]. Besides, the implementation of ICT may cause changes in nature of work of some employees, resulting in business process reengineering [31] and changes in organizational hierarchy [29]. A flexible culture plays an essential role in ensuring a smooth transition [32].

The second factor is organizational resources (O2), including human resources, financial resources, physical capital and IT resources. Specifically, organizations need to invest in new technology and equipment that enable the implementation of sustainability practices across the supply chain [23], as well as people with relevant professional expertise and skills $[20,30]$. Besides, the existing technology usage and technical capability of the organization are also significant, as the implementation of new systems depends on existing ICT infrastructure [30, 31].

Third, organizational strategy (O3) helps guide the daily operation and acts as a link between the internal resources and external demands [20]. It is discovered that incorporating the sustainability-related issues in the strategy not only enables the implementation of SSCM but also directly encourages employees to work on the sustainability mission [23]. Moreover, it suggests that successful implementation of technologies in supply chain requires a strategic alignment between IT and business objectives [27].

Fourth, top management commitment (O4) refers to the internal political power that encourages proactive sustainability practices and supporting ICTs [20]. This factor is recognized to be crucial for the implementation of SSCM practices [25, 33] and IT to support SCM [27, 29]. Since top management is responsible for developing organizational strategy and policies, they are more likely to make sustainability a priority if they are convinced of future benefits [20].

Fifth, employees' involvement (O5) during implementation stage has a positive impact on organization's sustainable supply chain performance [23] and technology adoption [27, 30]. Employees are expected to update their skills in both the field of SSCM practices and the use of relevant technologies and systems [30], resulting in fewer errors and waste and better sustainability-related performance.

The sixth factor is the organization's reputation (O6). It is claimed that a positive brand image leads to high morale among the employees and increased sales [20] because employees feel proud to work for a sustainable organization and customers prefer companies that produce sustainable products and implement sustainability initiatives [34]. 
The seventh factor is investor pressure (O7). Investors who place importance on sustainability tend to invest in sustainable businesses and withdraw investments once the businesses' sustainability performance is beyond their expectations $[20,26,34]$.

Overall, 14 adoption factors have been identified from the literature. It should be noted these factors are neutral, which means they can either positively or negatively influence the adoption of ICT-enabled SSCM practices. For example, as discussed above, SC partners' lack of sustainability knowledge is a barrier, while their sufficient knowledge can be a driver.

\section{The multiple case studies}

Given that our research question is a "what" question, survey and case study methods would be appropriate [35]. Since ICT-enabled SSCM practices are currently understudied, an in-depth exploration of the study context, encompassing issues at four levels: national, industry, supply chain and organizational, is necessary to identify possible influential factors. Therefore, case study is considered more suitable than survey for this study. To enhance the generalizability of the study findings, multiple case studies instead of a single case study is adopted.

\subsection{Overview of case organizations}

Three Australian food organizations of different sizes were involved (Table 1). They had been actively engaged in sustainability activities and proactively disclosed their sustainability performance.

Table 1. Summary of case organizations

\begin{tabular}{|c|c|c|c|}
\hline Organization & Type & $\begin{array}{c}\text { Sub- } \\
\text { sector }\end{array}$ & $\begin{array}{c}\text { No. of } \\
\text { employees }\end{array}$ \\
\hline C1 & Producer & Beef & 36 \\
\hline C2 & Manufacturer & Beverage & 3,500 \\
\hline C3 & Manufacturer & $\begin{array}{c}\text { Food \& } \\
\text { beverage }\end{array}$ & 5,300 \\
\hline
\end{tabular}

Case organization $1(\mathrm{C} 1)$ is a small-sized organic beef producer in Australia. With a mission to help people live better and healthier lives, the organization launched a sustainability program in 2015 to better manage the environment, animals, people and product in an ethical and sustainable way. $\mathrm{C} 1$ is the only Australian beef organization that joins the UN Global Compact. Case organization 2 (C2) is one of the world's largest wine manufacturers, which owns an international portfolio of more than 70 wine brands and sells wines in more than 70 countries around the world. C2 is also a signatory of the UN Global
Compact, and its sustainability program focuses on four key pillars: performance, planet, people and product. Case company 3 (C3) is a leading food and beverage manufacturer in Australasia, who owns various brands known by Australian and New Zealand consumers. Its commitment to sustainability and trust has been embedded in the organizational strategy, including three key areas of focus: be sociable and live well, tread lightly, and grow positive impacts.

\subsection{Data collection and analysis}

Data were collected from multiple sources, including published organizational documents (e.g., sustainability reports) and semi-structured interviews. We purposefully selected relevant participants from each case organization (managing director, sustainability manager and data governance lead) whose responsibilities are highly relevant to ICTenabled SSCM. An interview protocol consisting of 20 questions was developed to guide the data collection. Specifically, the questions covered a) SSCM practices adopted by the organizations, b) factors affecting the adoption of the SSCM practices, and c) how each factor contributes to the adoption of SSCM practices.

In the data analysis phase, "NVivo 12" was used to organize and manage the collected data. First, all the collected documents and interview transcripts were compiled and imported into the software. Nodes were then developed based on the ICT-enabled SSCM practices and influential factors identified in the literature. Next, within-case analysis was conducted. Data from each case was coded to the corresponding node, and any new node was added if new themes emerged. Finally, we conducted a cross-case analysis to identify similarities and differences in the factors, as well as the relationship between influential factors and ICT-enabled SSCM practices. The data were also compared to the previous literature in search of any consistency and contradiction.

\subsection{Research rigor}

We followed the criteria suggested by Yin [35] to ensure research rigor. First, construct validity is addressed through reviewing relevant literature, collecting evidence from multiple sources, and using case study repository to maintain a chain of evidence. Second, to enhance external validity, we followed a literal replication logic in selecting case companies, and ultimately selected three companies of different sizes and from different sub-sectors that have engaged in SSCM practices to increase the generalizability of our findings. To ensure reliability, a case study protocol was used to guide all the interviews and the 
documentation process. Moreover, a case study repository was used to store all relevant research data, including interview transcripts, notes, etc. Finally, a pilot interview with a managing director of a food organization was conducted to ensure that the interview questions are appropriate [35].

\section{Research findings}

We identified a set of factors affecting the adoption of ICT-enabled SSCM practices in each case organization (Table 2). First, the findings show that all the organizations practice sustainable sourcing, processing, packaging, distribution, and marketing.
Second, it is interesting to discover that most factors identified in the literature were found to be relevant in driving the organizations to adopt SSCM practices. Only competitive pressure (I2) has no effect on adoption. Furthermore, two new factors emerged from the case studies: environmental uncertainties (N4) at national level and the ICT resources of supply chain partners (SC3) at supply chain level. Environmental uncertainties are unpredictable events and the changes in social, economic, environmental and technological conditions, while the ICT resources of supply chain partners refers to the ICT-based resources such as databases, systems, and applications owned by the supply chain partners.

Table 2. Summary of research findings

\begin{tabular}{|c|c|c|c|c|c|c|c|c|c|c|c|c|c|c|c|}
\hline \multirow[t]{2}{*}{$\begin{array}{l}\text { SSCM } \\
\text { Practices }\end{array}$} & \multicolumn{3}{|c|}{$\begin{array}{c}\text { Sustainable } \\
\text { Sourcing }\end{array}$} & \multicolumn{3}{|c|}{$\begin{array}{c}\text { Sustainable } \\
\text { Processing }\end{array}$} & \multicolumn{3}{|c|}{$\begin{array}{c}\text { Sustainable } \\
\text { Packaging }\end{array}$} & \multicolumn{3}{|c|}{$\begin{array}{c}\text { Sustainable } \\
\text { Distribution }\end{array}$} & \multicolumn{3}{|c|}{$\begin{array}{c}\text { Sustainable } \\
\text { Marketing }\end{array}$} \\
\hline & $\mathrm{C} 1$ & $\mathrm{C} 2$ & $\mathrm{C} 3$ & $\mathrm{C} 1$ & $\mathrm{C} 2$ & $\mathrm{C} 3$ & $\mathrm{C} 1$ & $\mathrm{C} 2$ & $\mathrm{C} 3$ & $\mathrm{C} 1$ & $\mathrm{C} 2$ & $\mathrm{C} 3$ & $\mathrm{C} 1$ & $\mathrm{C} 2$ & $\mathrm{C} 3$ \\
\hline Legislation (N1) & $\checkmark$ & & & & & & & $\checkmark$ & $\checkmark$ & & & $\checkmark$ & & $\checkmark$ & $\checkmark$ \\
\hline Government support (N2) & & & & & & & & & & & & & & & $\checkmark$ \\
\hline Societal pressure (N3) & $\checkmark$ & $\checkmark$ & $\checkmark$ & $\checkmark$ & $\checkmark$ & $\checkmark$ & $\checkmark$ & $\checkmark$ & $\checkmark$ & $\checkmark$ & $\checkmark$ & $\checkmark$ & $\checkmark$ & $\checkmark$ & $\checkmark$ \\
\hline Environmental uncertainties (N4)* & & $\checkmark$ & & & $\checkmark$ & & & & & & & & & & \\
\hline Industry standards and associations (I1) & $\checkmark$ & & & $\checkmark$ & & & $\checkmark$ & $\checkmark$ & $\checkmark$ & $\checkmark$ & & & & $\checkmark$ & $\checkmark$ \\
\hline \multicolumn{16}{|l|}{ Competitive pressure (I2) } \\
\hline Knowledge of SC partners (SC1) & $\checkmark$ & & & & & & & & & & & $\checkmark$ & & & $\checkmark$ \\
\hline Cooperation of SC partners (SC2) & $\checkmark$ & $\checkmark$ & $\checkmark$ & $\checkmark$ & & & & $\checkmark$ & $\checkmark$ & & & $\checkmark$ & & & \\
\hline ICT resources of SC partners (SC3) * & $\checkmark$ & & & $\checkmark$ & & & & & & & $\checkmark$ & $\checkmark$ & & & \\
\hline Organizational culture $(\mathrm{O} 1)$ & $\checkmark$ & $\checkmark$ & $\checkmark$ & $\checkmark$ & $\checkmark$ & $\checkmark$ & $\checkmark$ & $\checkmark$ & $\checkmark$ & $\checkmark$ & $\checkmark$ & $\checkmark$ & $\checkmark$ & $\checkmark$ & $\checkmark$ \\
\hline Organizational resources $(\mathrm{O} 2)$ & $\checkmark$ & $\checkmark$ & $\checkmark$ & $\checkmark$ & $\checkmark$ & $\checkmark$ & $\checkmark$ & $\checkmark$ & $\checkmark$ & $\checkmark$ & $\checkmark$ & $\checkmark$ & $\checkmark$ & $\checkmark$ & $\checkmark$ \\
\hline Organizational strategy $(\mathrm{O} 3)$ & $\checkmark$ & $\checkmark$ & $\checkmark$ & $\checkmark$ & $\checkmark$ & $\checkmark$ & $\checkmark$ & $\checkmark$ & $\checkmark$ & $\checkmark$ & $\checkmark$ & $\checkmark$ & $\checkmark$ & $\checkmark$ & $\checkmark$ \\
\hline Top management commitment (O4) & & $\checkmark$ & $\checkmark$ & & $\checkmark$ & $\checkmark$ & & $\checkmark$ & $\checkmark$ & & $\checkmark$ & $\checkmark$ & & $\checkmark$ & $\checkmark$ \\
\hline Employees' involvement (O5) & & $\checkmark$ & & & $\checkmark$ & & & $\checkmark$ & & & & & & $\checkmark$ & $\checkmark$ \\
\hline Reputation (O6) & $\checkmark$ & $\checkmark$ & $\checkmark$ & $\checkmark$ & $\checkmark$ & $\checkmark$ & $\checkmark$ & $\checkmark$ & $\checkmark$ & $\checkmark$ & $\checkmark$ & $\checkmark$ & $\checkmark$ & $\checkmark$ & $\checkmark$ \\
\hline Investor pressure $(\mathrm{O} 7)$ & & $\checkmark$ & & & $\checkmark$ & & & $\checkmark$ & & & $\checkmark$ & & & $\checkmark$ & \\
\hline
\end{tabular}

* new factor

Further analysis of the results shows that none of the SSCM practices is influenced by all the 16 factors. Sustainable sourcing is affected by a large number of factors (14 out of 16), whereas sustainable packaging is affected by the least number of factors (11). Eight factors (i.e., N3, I1, O1, O2, O3, O4, O6 and O7) affect all types of sustainable practices, demonstrating their importance to ICT-enabled SSCM practice adoption. Factors at organizational level appear to be more important than those at other levels since six of the eight influential factors are at this level. How each type of the sustainable practices is affected by the 15 factors is explained below.

\subsection{Sustainable sourcing}

Sustainable sourcing practices are impacted by 14 factors. Specifically, factors N3, SC2, O1, O2, O3 and O6 have the highest impacts because they have been observed in all the cases. Factor $\mathrm{O} 4$ has moderate impacts as it is identified in two cases, while factors $\mathrm{N} 1, \mathrm{~N} 4, \mathrm{I} 1, \mathrm{SC} 1, \mathrm{SC} 3, \mathrm{O} 5$ and $\mathrm{O} 7$ have the lowest 
impacts since they are only identified in one case. Below are examples of how some of factors affect the adoption of ICT-enabled sustainable sourcing.

First, for societal pressure (N3) factor, C1 and C2 are signatories of the UN Global Compact, which means they are expected to integrate the UN Global Compact's ten principles on human rights, labor, environment, and anti-corruption into not only their business operation but also their supplier base. Moreover, since $\mathrm{C} 2$ and $\mathrm{C} 3$ own some of Australia and New Zealand's most famous brands in beverage, dairy and wine, they are under constant scrutiny from NGOs, media and consumers. Such pressure makes case organizations select and assess their suppliers more strictly to ensure none of them get involved in sustainability scandals.

Second, for cooperation of supply chain partners (SC2) factor, all case organizations implemented online self-assessment tools to assist suppliers in benchmarking their practices against industry best practices and the suppliers' code of conduct. As a result, suppliers can identify areas that need to be improved and enhance their sustainable performance. Besides, $\mathrm{C} 1$ and $\mathrm{C} 3$ deliver online training sessions about farm safety to their suppliers. The training provided by $\mathrm{C} 1$ included webinars and a series of engaging online courses that provided a sound knowledge base and awareness of hazards when working on rural properties.

\section{"By using the online self-assessment and planning tool, farmers can compare their sustainability performances to peers and the industry average and identify areas that need to be improved." (Managing director, C1)}

Third, regarding ICT resources of supply chain partners (SC3) factor, the case studies show that the lack of ICT resources would inhibit the integration and ICT-enablement of the supply chain so players along the supply chain are expected to invest in ICT resources and strengthen their ICT capabilities. For example, $\mathrm{C} 1$ launched a project to improve Internet connectivity for remote primary farmers. By implementing routers and DIY Wi-Fi antenna kits, the reliable Internet connection makes it possible for farmers to engage online safety training sessions and have access to online assessment tools.

Finally, for environmental uncertainties (N4) factor, due to the bushfire, C2 commenced a more detailed Climate Scenario Analysis to identify risks and mitigate the possible adverse impacts of climate change. For example, new technologies were invested to capture key vineyard data points, which provides more detailed information about the impact of climate change. Moreover, in the face of the COVID-19 pandemic, they introduced additional initiatives to ensure the safety, health and wellbeing of their employees working in vineyards and winery facilities.

\subsection{Sustainable processing}

Twelve factors were found relevant to this type of sustainable practices, five of which (N3, O1, O2, O3 and O6) have the greatest impacts. Factor $\mathrm{O} 4$ has moderate impacts, while the influence of $\mathrm{N} 4, \mathrm{I} 1, \mathrm{SC} 2$, $\mathrm{SC} 3, \mathrm{O} 5$ and $\mathrm{O} 7$ is relatively mild. Three examples are provided below.

First, in terms of societal pressure (N3) factor, as suggested in the case organizations' sustainability reports, all three organizations aligned their sustainability pillars with selected United Nations Sustainable Development Goals (SDG's). One common SDG is "sustainable consumption and production", which is closely related to the food processing phase. The case organizations are under pressure to minimize the energy consumption and food loss and waste during production.

Second, regarding organizational strategy (O3) factor, all case organizations incorporated their sustainable-related goals and strategies into the overall organizational strategy, which could affect the adoption of all the sustainable practices. In terms of sustainable processing, C3 reached a significant milestone in its carbon reduction target stated in the organizational strategy by adopting a 'whole brewery' carbon reduction program in its breweries in Australia.

\section{"Our central objective is measured by the value we provide to society. We exist to help people live better lives. Sustainability is at the core of achieving our business strategy." (Sustainability manager, C2)}

Third, for organizational resources $(\mathrm{O} 2)$ factor, the case studies indicate that the investment in technological improvements and infrastructure enabled $\mathrm{C} 2$ and $\mathrm{C} 3$ to produce their products in an environmentally and socially responsible manner. Specifically, C2 implemented innovative technologies to reduce the energy and water consumption significantly as well as reducing the chemical usage. The implementation of Safety Management System contributed to the reduction in the number of employees injured at C3's breweries.

\subsection{Sustainable packaging}

Sustainable packaging practices have been affected by 11 factors. Factors like N3, I1, O1, O2, O3 and $\mathrm{O} 6$ have an impact on all cases. Factors N1, SC2 and $\mathrm{O} 4$ have moderate influence while $\mathrm{O} 5$ and $\mathrm{O} 7$ have relatively minor impacts. 
In Australia, businesses with an annual turnover of \$5 million or more who consume packaging and packaged products should compulsorily comply with Australian Packaging Covenant (APC). The Covenant aims to reduce the negative environmental impact caused by packaging. Such legal requirements (N1) and the close cooperation with industry partners (e.g., Australian Packaging Covenant Organization) (I1) enabled $\mathrm{C} 2$ and $\mathrm{C} 3$ to adopt more initiatives to minimize their packaging environmental impact.

For cooperation of supply chain partners (SC2) factor, the case studies revealed that $\mathrm{C} 2$ and $\mathrm{C} 3$ cooperated with their packaging material suppliers to launch a number of projects to reduce the use of sustainable materials. For example, C2 commenced a glass weight review and successfully used lighter weight glass in over 70 individual product lines, while C3 established a clear baseline for recycled content with suppliers and a large volume of glass, paperboard, glue and yogurt pouch were eliminated.

In terms of organizational resources (O2) factor, $\mathrm{C} 2$ invested in innovative technologies to reduce water consumption in the packaging process, and in the development and optimization of packaging formats to improve the package design. In order to quantify the environmental impacts of packaging more accurately, C3 implemented a life cycle assessment (LCA) tool to monitor every phase of the packaging life cycle of both new and existing products. The LCA application was integrated into the ERP system to make the full use of the collected data.

\subsection{Sustainable distribution}

Sustainable distribution practices of the case organizations were found to be affected by 12 factors. Specifically, factors N3, O1, O2, O3 and O6 have an influence on all cases. Factors SC3 and $\mathrm{O} 4$ have moderate impacts by affecting two cases, while the impacts of factors N1, I1, SC1, SC2 and $\mathrm{O} 7$ are minimal as they only impact one case.

For example, in terms of ICT resources of supply chain partners (SC3) factor, C3 was required to comply with a law called Chains of Responsibility (CoR). Under this law, supply chain partners share the responsibility for ensuring that the Heavy Vehicle National Law (HVNL) is complied. A transportation management system (TMS) was implemented by them and their cooperated trucking companies to share the delivery location, delivery time, loading requirements and other relevant information about the delivery, which helps ensure compliance, optimize the truck loads and transport the products in a safe and efficient way. With C2, the improved logistics applications were adopted in the vineyard to optimize truck scheduling, resulting in less shipping cost, energy consumption and carbon emissions.

Furthermore, for organizational resources (O2) factor, the case studies indicate that the sufficient financial resources enabled C2 to locate their new expanded warehouse and distribution facility near the major roads, rail and shipping routes, resulting in less shipping cost and carbon emissions. Meanwhile, C3 invested around \$2 million in implementing solar power systems in its brewery sites and new distribution centers. The renewable electricity generated by these systems could reduce more than 1,000 tones of sites' emissions.

\subsection{Sustainable marketing}

Twelve factors were found relevant to sustainable marketing practices. Factors N3, O1, O2, O3 and 06 have the greatest impacts. Factors N1, I1, O4 and O5 have moderate impacts, while the influence of $\mathrm{N} 2$, $\mathrm{SC} 1$ and $\mathrm{O} 7$ has the least impacts. Below are examples that demonstrate how some of these factors affect the adoption of ICT-enabled sustainable marketing.

First, in terms of organizational resources (O2) factor, the access to the internet and social media sites as well as the ability to design and maintain the websites make it feasible for all case companies to publicize companies' sustainable practices and activities and actively get stakeholders involved in the dialogue to get feedback from them.

Second, for organizational strategy (O3) factor, the case studies show that customers' health and needs are the main focus of the organizational strategy among all case organizations. Keeping customers satisfied with their products motivates case organizations to adopt sustainable marketing related initiatives. For example, C2 and C3 provided transparent product labelling information, in terms of both nutritional and alcohol content, to assist consumers to make informed purchasing decisions.

Third, regarding employees' involvement (O5), the training provided to employees enabled $\mathrm{C} 2$ and $\mathrm{C} 3$ to comply with their responsible marketing standards and promote responsible consumption to customers. For, instance, employees working in the marketing and sales department of C3 were trained to ensure their selling behavior met the requirements of consumer

\section{Discussion}

\subsection{Addressing the research question}

Fifteen factors from different levels are found to impact the adoption of ICT-enabled SSCM practices 
in the Australian food industry. At the national level, factors include legislation, government support, and societal pressure. A new factor is identified at this level: environmental uncertainties. At industry level, the influence of industry standards and associations is identified in the case studies. However, competitive pressure, though noted in the previous literature, is not found relevant in this study. At supply chain level, both the knowledge and cooperation of the supply chain partners are verified in the case studies. Besides, the case studies reveal a new important factor namely the ICT resources of supply chain partners. Organizational level has the greatest number of influential factors, including organizational culture, organizational resources, organizational strategy, top management commitment, employees' involvement, reputation, and investor pressure.

The newly identified factor the ICT resources of supply chain partners (SC3), has actually been recognized in previous studies in the context supply chain management in general. It is claimed that having poor ICT infrastructure facilities would inhabit the integration and supply chain $[27,29]$. Therefore, each player in the supply chain should make its own contribution by investing in ICT resources on its premises as well as to ensure the interoperability of ICT applications so that the communication, performance and traceability of whole supply chain could be improved [32]. These aspects are also essential for sustainable supply chain management (SSCM) enabled by ICT.

Another new factor environmental uncertainty (N4) was observed in C2 only and had limited impact on its sustainable sourcing and processing practices. One possible reason is that wine production is the main business of $\mathrm{C} 2$, and the climate patten changes could significantly affect the growing and processing of grapes. Thus, urgent actions were taken by $\mathrm{C} 2$ to manage its climate-related risks.

As mentioned above, competitive pressure (I2) is found to be irrelevant to all kinds of sustainable practices in this study. There may be several reasons. First, since the three case organizations are either the major players in the food industry or the pioneers in adopting the SSCM practices, they are the ones who outperformed other companies. Therefore, they could be the ones who put pressure on other organizations in their supply chains or the food industry to adopt ICTenabled SSCM practices. Second, Australia is a multicultural country and has diverse customer bases [36]. Food organizations could differentiate themselves in various ways, and hence, being sustainable is merely one of the many options. Third, compared to the European countries, the development of sustainability in Australia is still in the initial stage
[6]. Therefore, the sustainability initiative in the Australian food industry is relatively less mature, and thus there is no fierce competition in pursuing sustainable practices at this stage.

In this study, we further investigate the level of influence of the 15 factors on ICT-enabled SSCM practices based on the number of cases each factor has impacted (Figure 1). Factors identified to have a low level of influence are only observed in one case. Those verified in two cases are labelled as having moderate influence. Factors with a high level of influence are those affected all three cases.

As shown in Figure 1, nine factors are found to have high level of influence, including legislation (N1), societal pressure (N3), industry standards and association (I1), the cooperation of supply chain partners (SC2), the ICT resources of supply chain partners (SC3), organizational culture (O1), organizational resources $(\mathrm{O} 2)$, organizational strategy (O3) and reputation (O6). This finding is consistent with that of Luthra et al. [33] who identified N1, SC3, $\mathrm{O} 2$ and $\mathrm{O} 3$ as factors that have relatively higher importance when adopting sustainable consumption and production initiatives in a supply chain compared to other factors. This findings is also consistent with Saeed and Kersten [20] who indicate that factors N1, $\mathrm{N} 3, \mathrm{O} 1, \mathrm{O} 2$ and $\mathrm{O} 3$ are particularly essential since they have a higher number of occurrences compared to other factors investigated in the previous studies.

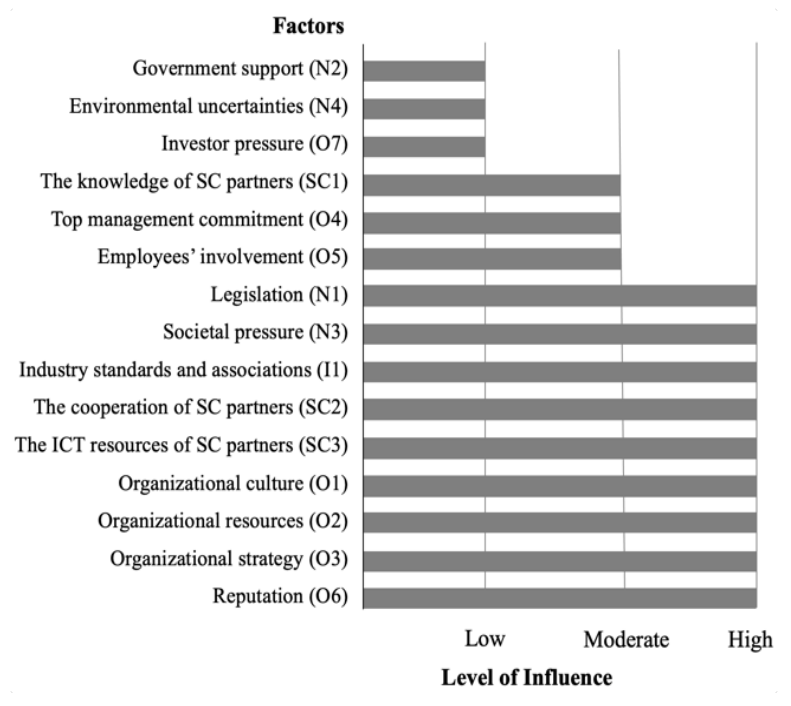

Figure 1. Level of influence for each factor

\subsection{Implications}

This study contributes to the current state of knowledge in the field of ICT-enabled SSCM in the following ways. First, it addresses the research gap related to limited studies investigating key factors 
affecting ICT-enabled SSCM practices adoption. We examined the 14 factors which are drawn from the studies on SSCM practices adoption. Thirteen factors are found to have an impact on the adoption of ICTenabled SSCM practices in the Australian food industry. Besides, we identified two new factors including environmental uncertainties and the ICT resources of supply chain partners. These factors bring new insights and complement the current understanding of ICT-enabled SSCM practices and the influential factors. Additionally, we analyzed the relationship between the factors and different types of sustainable practices, which provides further insight into the linkages between them.

This study also has several practical implications. By referring to the research findings, Australian food organizations can understand what factors may affect their adoption of ICT-enabled SSCM practices. Specifically, they can first identify what kind of sustainable practices they are going to adopt or adopting. Then, the linkage between the factors and sustainable practices explained in this paper can guide organizations to find out relevant factors at different levels. Furthermore, understanding the different levels of influence of those factors can guide organizations in prioritizing their effort and resources in addressing various factors affecting the adoption. As a result, the organizations are expected to be more prepared for the adoption of certain ICT-enabled SSCM practices, leading to successful SSCM practices implementation and improved organizational sustainability performance. Moreover, this research enhances other important stakeholders including government's current understanding of the Australian food industry SSCM practices and the influential adoption factors and thus helps them devise appropriate intervention strategies to promote the adoption of ICT-enabled SSCM practices within the industry.

\section{Conclusion}

This study investigates the factors affecting ICTenabled SSCM practices in the context of the Australian food industry. Thirteen out of 14 factors identified in previous studies are found to have an impact on ICT-enabled SSCM practices adoption in Australian food industry, and two new factors (environmental uncertainties and the ICT resources of supply chain partners) are identified in the multiple case studies. It is found that legislation (N1), societal pressure (N3), industry standards and association (I1), the cooperation of SC partners (SC2), the ICT resources of SC partners (SC3), organizational culture $(\mathrm{O} 1)$, organizational resources $(\mathrm{O} 2)$, organizational strategy (O3) and reputation (O6) have the most significant influence as they affect the adoption of ICT-enabled SSCM practices in all three case organizations of different sizes.

There are several limitations of this study. First, it only focuses on the Australian food industry. The applicability of the findings to other contexts, such as the manufacturing industry and developing countries would be limited. Besides, though the case organizations are of different sizes, the number of cases is relatively small, which would affect the generalizability of the findings. Third, although environmental uncertainties factor is identified as a new factor, it was only observed in one case organization and has limited impact on types of sustainable practices. More studies are needed to further examine the actual influence of this factor. Similarly, competitive pressure also requires further investigation to verify the impact of this factor since it has not been identified as an influential factor in this study. Future research involving other industries and countries with more case studies is needed for two reasons: a) future studies would complement the findings of this study and enhance the generalizability of the findings, and $b$ ) future studies would furnish an opportunity to discover new factors at the industry level which was not the case in this study.

\section{References}

[1] Millar, M., Global Supply Chain Ecosystems: Strategies for Competitive Advantage in a Complex, Connected World, Kogan Page Publishers, 2015.

[2] Kurnia, S. "Sustainable Supply Chain Management Adoption: Challenges and Opportunities", The 10th International Conference on Advanced Computer Science and Information Systems, Yogyakarta, Indonesia, 2018.

[3] Poore, J. and Nemecek, T., "Reducing Food's Environmental Impacts through Producers and Consumers", Science, 360(6392), 2018, pp. 987-992.

[4] Aung, M.M. and Chang, Y.S., "Traceability in a Food Supply Chain: Safety and Quality Perspectives", Food Control, 39, 2014, pp. 172-184.

[5] Seuring, S. and Müller, M., "From a Literature Review to a Conceptual Framework for Sustainable Supply Chain Management", Journal of Cleaner Production, 16(15), 2008, pp. 1699-1710.

[6] Kurnia, S., Rahim, M.M., Samson, D., and Prakash, S. "Exploring the Adoption of Sustainable Supply Chain Practices in Australia: Current Practices and Adoption Motivations", Pacific Asia Conference on Information Systems, Chengdu, China, 2014.

[7] Peng, X., Kurnia, S., and Cui, T. "IT-Enabled Sustainable Supply Chain Management Capability Maturity", Proceedings of the 54th Hawaii International Conference on System Sciences, 2021.

[8] Zhong, R., Xu, X., and Wang, L., "Food Supply Chain Management: Systems, Implementations, and Future 
Research", Industrial Management \& Data Systems, 117(9), 2017, pp. 2085-2114.

[9] Australian Trade and Investment Commission. Ensuring Food Safety and Quality with Leading-Edge Traceability Solutions. Insight: Safe, transparent food supply chains. 2019.

[10] Hassini, E., Surti, C., and Searcy, C., "A Literature Review and a Case Study of Sustainable Supply Chains with a Focus on Metrics", International Journal of Production Economics, 140(1), 2012, pp. 69-82.

[11] Ernst \& Young and United Nations Global Compact, "The State of Sustainable Supply Chains: Building Responsible and Resilient Supply Chains", 2016.

[12] Grant, D.B., Trautrims, A., and Wong, C.Y., Sustainable Logistics and Supply Chain Management: Principles and Practices for Sustainable Operations and Management, Kogan Page Publishers, 2017.

[13] Yawar, S.A. and Seuring, S., "Management of Social Issues in Supply Chains: A Literature Review Exploring Social Issues, Actions and Performance Outcomes", Journal of Business Ethics, 141(3), 2017, pp. 621-643.

[14] Zailani, S., Jeyaraman, K., Vengadasan, G., and Premkumar, R., "Sustainable Supply Chain Management (Sscm) in Malaysia: A Survey", International journal of production economics, 140(1), 2012, pp. 330-340.

[15] Sarghini, F., Erdogdu, F., and Accorsi, R., Designing Advanced Food Packaging Systems and Technologies through Modeling and Virtualization, in Sustainable Food Supply Chains: Planning, Design, and Control through Interdisciplinary Methodologies, 2019, pp. 83104.

[16] Blanco, E.E. and Sheffi, Y., Green Logistics, in Sustainable Supply Chains: A Research-Based Textbook on Operations and Strategy, Springer International Publishing: Cham, 2017, pp. 147-187.

[17] Ackerley, N., Sertkaya, A., and Lange, R., "Food Transportation Safety: Characterizing Risks and Controls by Use of Expert", Food Protection Trends, 30(4), 2010, pp. 212-222.

[18] Soler, C., "Conceptualizing Sustainably Produced Food for Promotional Purposes: A Sustainable Marketing Approach", Sustainability, 4(3), 2012, pp. 294-340.

[19] Kurnia, S., Parker, C., Ali, M., and Karnali, R., "The Impact of Multilevel Contextual Factors on IS Adoption at the Inter-Organizational Level", Communications of the Association for Information Systems, 44, 2019, pp. 421-459.

[20] Saeed, M. and Kersten, W., "Drivers of Sustainable Supply Chain Management: Identification and Classification", Sustainability, 11(4), 2019, p. 1137.

[21] Sajjad, A., Eweje, G., and Tappin, D., "Sustainable Supply Chain Management: Motivators and Barriers", Business Strategy and the Environment, 24(7), 2015, pp. 643-655.

[22] Jia, F., Zuluaga-Cardona, L., Bailey, A., and Rueda, X., "Sustainable Supply Chain Management in Developing Countries: An Analysis of the Literature", Journal of Cleaner Production, 189,, 2018, pp. 263-278.
[23] Oelze, N., "Sustainable Supply Chain Management Implementation-Enablers and Barriers in the Textile Industry", Sustainability, 9(8), 2017, pp. 1435-1450.

[24] Lesca, N., Caron-Fasan, M.-L., Loza-Aguirre, E., and Chalus-Sauvannet, M.-C., "Drivers and Barriers to PreAdoption of Strategic Scanning Information Systems in the Context of Sustainable Supply Chain", Systèmes d'Information et Management, 20(3), 2015, pp. 9-46.

[25] Emamisaleh, K. and Rahmani, K., "Sustainable Supply Chain in Food Industries: Drivers and Strategic Sustainability Orientation", Cogent Business \& Management, 4(1), 2017, pp. 1-18.

[26] León-Bravo, V., Caniato, F., and Caridi, M., "Sustainability Assessment in the Food Supply Chain: Study of a Certified Product in Italy", Production Planning \& Control, 2020, pp. 1-18.

[27] Arora, R., Haleem, A., and Farooquie, J.A., "Impact of Critical Success Factors on Successful Technology Implementation in Consumer Packaged Goods (Cpg) Supply Chain", Management Science Letters, 7(5), 2017, pp. 213-224.

[28] Morali, O. and Searcy, C., "A Review of Sustainable Supply Chain Management Practices in Canada", Journal of Business Ethics, 117(3), 2012, pp. 635-658.

[29] Jharkharia, S. and Shankar, R., "IT-Enablement of Supply Chains: Understanding the Barriers", Journal of Enterprise Information Management, 18(1), 2005, pp. 11-27.

[30] Arora, R., Haleem, A., and Farooquie, J.A. "Barriers Affecting Successful Technology Enablement of Supply Chain- an Indian Perspective", IOP Conference Series: Materials Science and Engineering, 2018.

[31] Gunasekaran, A. and Ngai, E.W.T., "Information Systems in Supply Chain Integration and Management", European Journal of Operational Research, 159(2), 2004, pp. 269-295.

[32] Singh, R.K., Luthra, S., Mangla, S.K., and Uniyal, S., "Applications of Information and Communication Technology for Sustainable Growth of SMEs in India Food Industry", Resources, Conservation and Recycling, 147, 2019, pp. 10-18.

[33] Luthra, S., Mangla, S.K., Xu, L., and Diabat, A., "Using Ahp to Evaluate Barriers in Adopting Sustainable Consumption and Production Initiatives in a Supply Chain", International Journal of Production Economics, 181(Part B), 2016, pp. 342-349.

[34] Chkanikova, O. and Mont, O., "Corporate Supply Chain Responsibility: Drivers and Barriers for Sustainable Food Retailing", Corporate Social Responsibility and Environmental Management, 22(2), 2015, pp. 65-82.

[35] Yin, R.K., Designing Case Studies: Identifying Your Case(S) and Establishing the Logic of Your Case Study, in Case Study Research and Applications: Design and Methods, SAGE Publications: California, United States, 2018.

[36] Kurnia, S. and Johnston, R.B., "Adoption of Efficient Consumer Response: Key Issues and Challenges in Australia", Supply Chain Management: An International Journal, 8(3), 2003, pp. 251-262. 